\title{
In vitro susceptibility to antifungal agents of environmental Cryptococcus spp. isolated in the city of Ribeirão Preto, São Paulo, Brazil
}

\author{
Reginaldo dos Santos Pedroso ${ }^{+}$, Joseane Cristina Ferreira, Regina Celia Candido
}

Laboratório de Micologia Clínica, Departamento de Análises Clínicas, Toxicológicas e Bromatológicas, Faculdade de Ciências

Farmacêuticas de Ribeirão Preto, Universidade de São Paulo, Via do Café, s/nº, 14040-903 Ribeirão Preto, SP, Brasil

Infections by Cryptococcus strains other than $\mathrm{C}$. neoformans have been detected in immunocompromised patients. Of these strains, three are considered human pathogens: C. albidus, C. laurenttii, and C. uniguttulatus. This study deals with the in vitro susceptibility of Cryptococcus to drugs such as amphotericin B, itraconazole, fluconazole, and 5-fluorocytosine. Environmental Cryptococcus isolates (50) distributed as follows: C. neoformans var. neoformans (16), C. albidus (17), C. laurentii (14), and C. uniguttulatus (3) were evaluated by the micro and macrodilution techniques, according to EUCAST and NCCLS recommendations, respectively. Considering both methodologies the respective minimal inhibitory concentrations (MIC) were 0.125 and $2 \mu \mathrm{g} / \mathrm{ml}$ for amphotericin $\mathrm{B}, 0.06$ and $8 \mu \mathrm{g} /$ $\mathrm{ml}$ for itraconazole, and 0.5 and more than $64 \mu \mathrm{g} / \mathrm{ml}$ for fluconazole and 5-fluorocytosine. Agreement percentages for the two methodologies were $100 \%$ for amphotericin B and fluconazole for all the strains tested. For itraconazole, the agreement percentage was $81.3 \%$ in the C. neoformans strain and 100\% for all the others. All species had a agreement percentage of 94.1 to $100 \%$ when susceptibility to 5-fluorocytosine was tested. It is concluded that environmental isolates of C. neoformans var. neoformans, C. albidus, C. laurentii, and C. uniguttulatus may show high MICs against certain drugs, suggesting in vitro primary resistance to the antifungals tested.

Key words: antifungals - Cryptococcus spp. - susceptibility - São Paulo - Brazil

Infections by Cryptococcus species other than $C$. neoformans are seldom described in the literature, but they do occur in immunocompromised patients, with hematological or oncologic diseases or are human immunodeficiency virus infected. Among the infective species, three are considered human pathogens, C. albidus, $C$. laurentii, and C. uniguttulatus (Johnson et al. 1998, McCurdy \& Morrow 2001). Variable clinical manifestations are reported, such as instances of cutaneous infections (Kamalam et al. 1977, Johnson et al. 1998), ventriculitis (McCurdy \& Morrow 2001), meningitis (Kordossis et al. 1998), fungemia (Loison et al. 1996, Johnson et al. 1998, Kordossis et al. 1998, Kunova \& Krcmery 1999), pneumonia and pulmonary abscesses (Johnson et al. 1998).

The species in vitro susceptibility to antifungals is also not well known, although it is very important that this type of previous information guide the clinician in his choice of antifungals to a certain group of microorganisms (Aller et al. 2000).

Cryptococcus susceptibility studies reported so far are mostly related to clinical or environmental $C$. neoformans, while other clinically important species are poorly described (Franzot \& Hamdan 1996, Alves et al. 2001, Garcia-Martos et al. 2002, Moraes et al. 2003).

In this report the in vitro antifungal susceptibility of different environmental yeast species of the Cryptococ-

\footnotetext{
Financial support: Capes

${ }^{+}$Corresponding author: rpedroso@fcfrp.usp.br

Received 30 August 2005

Accepted 5 April 2006
}

cus genus was evaluated, utilizing in broth micro and macrodilution methods according to guidelines of the National Committee for Clinical Laboratory Standards (NCCLS 2002).

\section{MATERIALS AND METHODS}

Microorganisms tested-Environmental isolates in the city of Ribeirão Preto, state of São Paulo, Brazil, were distributed as follows: 16 C. neoformans var. neoformans, 17 C. albidus, 14 C. laurentii, and 3 C. uniguttulatus.

Susceptibility tests to antifungals - The antifungals tested were: amphotericin B (Fungizon, Bristol Myers Squibb do Brazil, Brazil), 5-fluorocytosine (Roche, Brazil), fluconazole (Pfizer, Sandwich, UK) and itraconazole (Janssen, Beerse, Belgium). Dimethyl sulfoxide (Vetec, Rio de Janeiro, Brazil) was used to prepare stock solutions of amphotericin B and itraconazole in the concentrations of $320 \mu \mathrm{g} / \mathrm{ml}$. Aqueous solutions of fluconazole and 5fluorocytosine, were prepared in sterile distilled water in the concentrations of $1280 \mu \mathrm{g} / \mathrm{ml}$. Drug final concentrations in the tests were 16 to $0.03 \mu \mathrm{g} / \mathrm{ml}$ for amphotericin B and itraconazole and 64 to $0.25 \mu \mathrm{g} / \mathrm{ml}$ for fluconazole and 5-fluorocytosine. The culture medium, RPMI-1640 containing L-glutamine, but no sodium bicarbonate was supplemented with glucose $(18 \mathrm{~g} / \mathrm{l})$ and buffered to $\mathrm{pH} 7$ with $0.165 \mathrm{M}$ morpholinepropanesulfonic acid (MOPS), according to EUCAST (2002) recommendations. The primary yeast inocula equivalent to 0.5 in the McFarland scale $\left(1\right.$ to $5 \times 10^{6}$ cells $\left./ \mathrm{ml}\right)$ were prepared in deionized sterile water according to NCCLS document M27-A2 (NCCLS 2002). The confirmation of inoculum sizes was determined with the final higher test inoculum for both macro and microdilution tests. These diluted yeast sus- 
pensions were mixed with a vortex, and diluted 1:10. One hundred microliter aliquots of the latter suspension were removed with a pipette, and this volume was spread onto a Sabouraud dextrose agar plate with a sterile, bent glass rod. Plates were incubated at 30 and $35^{\circ} \mathrm{C}$ during 5 days, and the CFU per milliliter were determined. This allowed counts of 10 to 50 colonies per plate (Espinel-Ingroff et al. 1992, Rodriguez-Tudela et al. 2000, EUCAST 2002, NCCLS 2002).

Macrodilution method - One hundred microliter aliquots of each drug dilution were mixed, in a glass tube $13 \times 100 \mathrm{~mm}$, with $900 \mu 1$ of the RPMI- 1640 containing 0.5 to $2.5 \times 10^{6} \mathrm{cells} / \mathrm{ml}$. Control tubes were prepared containing just drug diluents (negative controls) and others (positive controls) containing microorganism suspensions and drug diluents. All tubes, in duplicate, were incubated at $30^{\circ} \mathrm{C}$ during $48 \mathrm{~h}$, except for C. neoformans var. neoformans and the control strains incubated at $35^{\circ} \mathrm{C}$ for the same time. Growth in each test tube was compared to the equivalent controls without drugs. Minimal inhibitory concentration (MIC), for azoles and 5-fluorocytosine, was defined as the smallest concentration inhibiting at least 50\% of the control tube growth $(0.5 \mathrm{ml}$ of growth control plus $0.5 \mathrm{ml}$ of uninoculated RPMI), and for amphotericin B as the smallest concentration able to completely inhibit (100\%) growth.

Microdilution method - Ninety-six well plates containing $100 \mu \mathrm{l}$ aliquots of each drug dilution/well were stored at $-20^{\circ} \mathrm{C}$ for up to 30 days. The initial inoculum suspension, RPMI diluted $(1: 10)$ was the test material. In duplicate tests, $100 \mu \mathrm{l}$ of the diluted suspension was added to each of the wells in the plates containing the drug. Positive and negative controls were established in separate wells. The plates were incubated at $30^{\circ} \mathrm{C}$ except for $C$. neoformans var. neoformans and control strains, which were incubated at $35^{\circ} \mathrm{C}$. MIC, for azoles and 5fluorocytosine, was defined as the smallest concentration inhibiting at least $50 \%$ of the control tube growth, and for amphotericin B as the smallest concentration able to completely inhibit (100\%) growth.

Control microorganisms - Strains of Candida parapsilosis ATCC 22019 and C. krusei ATCC 6258 were used as controls.

Result analysis - The endpoints for fluconazole, itraconazole and 5-fluorocytosine were the ones suggested by NCCLS (2002) and the ones for amphotericin B by Rodriguez-Tudela et al. (1998). Microorganisms showing MICs $\geq 2 \mu \mathrm{g} / \mathrm{ml}$ were considered resistant to amphotericin $\mathrm{B}$; for itraconazole resistance was determined for MICs $\geq 1 \mu \mathrm{g} / \mathrm{ml}$, for 5 -fluorocytosine $\geq 32 \mu \mathrm{g} / \mathrm{ml}$ and $\geq 64$ $\mu \mathrm{g} / \mathrm{ml}$ for fluconazole. By comparing the values in the micro and macrodilution methods the correlation analysis between MICs for each drug and microorganism was established. The values were considered equivalent when both were equal or differed by at the most two dilutions (reference value \pm 2 dilutions). In other conditions the difference in values was expressed as units of dilution. Based on the result equivalence definition, the agreement percentage was calculated meaning the percentage of the total compared results, obtained in the two methods, considered as being equivalent (Pfaller \& Barry 1994).

\section{RESULTS}

Controls, C. parapsilosis ATCC 22019 and C. krusei ATCC 6258 showed MIC values according to the NCCLS (2002) described range. The MICs and MIC intervals for the four drugs inhibiting $50 \%$ and $90 \%$ of the isolates $\left(\mathrm{MIC}_{50}\right.$ and $\left.\mathrm{MIC}_{90}\right)$ are summarized in Tables I to IV.

Amphotericin B MIC range values were the smallest among the drugs tested and within the group C. laurentii was the largest (Table I). For itraconazole the widest MIC range was seen with $C$. neoformans var. neoformans, and C. albidus in both methods. The highest $\mathrm{MIC}_{50}$ and $\mathrm{MIC}_{90}$ were shown by C. albidus (Table II). Fluconazole had the highest MIC ranges in susceptibility tests with $C$. neoformans var. neoformans. The micro and macrodilution methods showed the highest $\mathrm{MIC}_{50}$ values for C. albidus; $\mathrm{MIC}_{90}$ values results were higher than $64 \mu \mathrm{g} / \mathrm{ml}$ for all strains, except $C$. laurentii, in both methods (Table III). 5fluorocytosine showed the widest MIC ranges for all strains, the smallest being with $C$. uniguttulatus (Table IV).

Table $\mathrm{V}$ shows agreement percentages (AP) for the results obtained by the micro and macrodilution methods. It can be seen that for $C$. neoformans var. neoformans the index was $100 \%$ against amphotericin B, fluconazole and 5-fluorocytosine, considering \pm 1 dilution, while for itraconazole the AP was 56.3 or $81.3 \%$ considering \pm 1 or \pm 2 dilutions respectively. For the other strains, AP was $100 \%$ against amphotericin B; APs of 82.3 and $100 \%$ were shown by $C$. albidus against itraconazole and 71.5 and $100 \%$ with $C$. laurentii considering \pm 1 and \pm 2 dilutions, respectively. To 5-fluorocytosine the AP was 88.2 and $94.1 \%$ for C. albidus, and 85.7 and $100 \%$ for C. laurentii,

TABLE I

In vitro susceptibility of 50 environmental Cryptococcus isolates to antifungal amphotericin B

\begin{tabular}{|c|c|c|c|c|c|c|}
\hline \multirow[b]{2}{*}{ Number of strains tested } & \multicolumn{3}{|c|}{ Macrodilution $(\mu \mathrm{g} / \mathrm{ml})$} & \multicolumn{3}{|c|}{ Microdilution $(\mu \mathrm{g} / \mathrm{ml})$} \\
\hline & Range & $\mathrm{MIC}_{50}$ & $\mathrm{MIC}_{90}$ & Range & $\mathrm{MIC}_{50}$ & $\mathrm{MIC}_{90}$ \\
\hline C. neoformans var. neoformans (16) & $0,25-2$ & 1 & 2 & $0,25-2$ & 1 & 2 \\
\hline C. albidus (17) & $0,25-1$ & 0,5 & 1 & $0,25-1$ & 1 & 1 \\
\hline C. laurentii (14) & $0,125-2$ & 0,5 & 2 & $0,125-2$ & 0,5 & 2 \\
\hline C. uniguttulatus (3) & $0,25-1$ & 0,25 & 1 & 0,5 & 0,5 & 0,5 \\
\hline
\end{tabular}

$\mathrm{MIC}_{50}$ and $\mathrm{MIC}_{90}$, MICs at which 50 and $90 \%$ of the strains, respectively, are inhibited. 
TABLE II

In vitro susceptibility of 50 environmental Cryptococcus isolates to the antifungal itraconazole

\begin{tabular}{|c|c|c|c|c|c|c|}
\hline \multirow[b]{2}{*}{ Number of strains tested } & \multicolumn{3}{|c|}{ Macrodilution $(\mu \mathrm{g} / \mathrm{ml})$} & \multicolumn{3}{|c|}{ Microdilution $(\mu \mathrm{g} / \mathrm{ml})$} \\
\hline & Range & $\mathrm{MIC}_{50}$ & $\mathrm{MIC}_{90}$ & Range & $\mathrm{MIC}_{50}$ & $\mathrm{MIC}_{90}$ \\
\hline C. neoformans var. neoformans (16) & $0,06-4$ & 0,25 & 1 & $0,06-8$ & 0,5 & 2 \\
\hline C. albidus (17) & $0,125-8$ & 2 & 8 & $0,06-8$ & 4 & 8 \\
\hline C. laurentii (14) & $0,06-1$ & 0,25 & 1 & $0,06-1$ & 0,5 & 1 \\
\hline C. uniguttulatus (3) & $0,25-8$ & 0,25 & 8 & $0,5-4$ & 0,5 & 4 \\
\hline
\end{tabular}

See Table I footnote

TABLE III

In vitro susceptibility of 50 environmental Cryptococcus isolates to the antifungal fluconazole

\begin{tabular}{|c|c|c|c|c|c|c|}
\hline \multirow[b]{2}{*}{ Number of strains tested } & \multicolumn{3}{|c|}{ Macrodilution $(\mu \mathrm{g} / \mathrm{ml})$} & \multicolumn{3}{|c|}{ Microdilution $(\mu \mathrm{g} / \mathrm{ml})$} \\
\hline & Range & $\mathrm{MIC}_{50}$ & $\mathrm{MIC}_{90}$ & Range & $\mathrm{MIC}_{50}$ & $\mathrm{MIC}_{90}$ \\
\hline C. neoformans var. neoformans (16) & $0,5->64$ & 4 & $>64$ & $0,5->64$ & 4 & $>64$ \\
\hline C. albidus (17) & $4->64$ & 16 & $>64$ & $2->64$ & 32 & $>64$ \\
\hline C. laurentii (14) & $0,5-32$ & 8 & 16 & $1-16$ & 4 & 16 \\
\hline C. uniguttulatus (3) & $1->64$ & 8 & $>64$ & $2->64$ & 4 & $>64$ \\
\hline
\end{tabular}

See Table I footnote

TABLE IV

In vitro susceptibility of 50 environmental Cryptococcus isolates to the antifungal 5-fluorocytosine

\begin{tabular}{|c|c|c|c|c|c|c|}
\hline \multirow[b]{2}{*}{ Number of strains tested } & \multicolumn{3}{|c|}{ Macrodilution $(\mu \mathrm{g} / \mathrm{ml})$} & \multicolumn{3}{|c|}{ Microdilution $(\mu \mathrm{g} / \mathrm{ml})$} \\
\hline & Range & $\mathrm{MIC}_{50}$ & $\mathrm{MIC}_{90}$ & Range & $\mathrm{MIC}_{50}$ & $\mathrm{MIC}_{90}$ \\
\hline C. neoformans var. neoformans (16) & $1->64$ & $>64$ & $>64$ & $1->64$ & $>64$ & $>64$ \\
\hline C. albidus (17) & $0,5->64$ & 32 & $>64$ & $0,5->64$ & $>64$ & $>64$ \\
\hline C. laurentii (14) & $2->64$ & 32 & $>64$ & $1->64$ & 32 & $>64$ \\
\hline C. uniguttulatus (3) & $16->64$ & $>64$ & $>64$ & $16->64$ & 32 & $>64$ \\
\hline
\end{tabular}

See Table I footnote

TABLE V

Agreement percentages between in broth micro and macrodilution methods for Cryptococcus spp. strains isolated from the environment in Ribeirão Preto, SP, Brazil

\begin{tabular}{llccc}
\hline $\begin{array}{l}\text { Species } \\
\text { (number of strains) }\end{array}$ & Antifungal & $\begin{array}{c}0 \text { dilution } \\
\%\end{array}$ & $\begin{array}{c}\text { dilution } \\
\%\end{array}$ & $\begin{array}{c}\text { dilution } \\
\%\end{array}$ \\
\hline $\begin{array}{l}\text { C. } \text { neoformans var. neoformans } \\
\text { (16) }\end{array}$ & Amphotericin B & 62.5 & 100 & 100 \\
& Itraconazole & 6.3 & 56,3 & 100 \\
& Fluconazole & 43.8 & 100 & 1.3 \\
C. albidus & 5-fluorocytosine & 93.8 & 100 & 100 \\
(17) & Amphotericin B & 35.3 & 82.3 & 100 \\
& Itraconazole & 41.2 & 88.2 & 100 \\
& Fluconazole & 47.1 & 100 & 94.1 \\
C. laurentii & 5-fluorocytosine & 58.8 & 71.5 & 100 \\
(14) & Amphotericin B & 50 & 100 & 100 \\
& Itraconazole & 28.6 & 85.7 & 100 \\
Fluconazole & 21.4 & 100 & 100 \\
(3) & 5-fluorocytosine & 64.3 & 100 & 100 \\
& Amphotericin B & 33.3 & 100 & 100 \\
\hline
\end{tabular}


\pm 1 and \pm 2 dilutions respectively. AP was $100 \%$ for both dilutions when $C$. uniguttulatus was tested against the four antifungals studied. The smallest APs were found for itraconazole and the strains $C$. neoformans var. neoformans and $C$. laurentii in dilution \pm 1 .

\section{DISCUSSION}

Antifungal susceptibility data of non $C$. neoformans strains are scarce in the literature, even if one considers strains isolated from patients (Kordossis et al. 1998, Bauters et al. 2001, Chen et al. 2001, McCurdy \& Morrow 2001, Averbuch et al. 2002, Garcia-Martos et al. 2002, Quindos et al. 2004). The amphotericin B results obtained in both methods tested in this study indicated a similar MIC range. A small number of $C$. neoformans var. neoformans strains showed MIC values of $2 \mu \mathrm{g} / \mathrm{ml}$ suggesting in vitro resistance to the antifungal. Amphotericin B high MIC values for environmental $C$. neoformans var. neoformans have not been reported previously (Franzot \& Hamdan 1996, Garcia-Martos et al. 2002, Moraes et al. 2003, Souza et al. 2005). For C. albidus, and $C$. uniguttulatus the MICs confirm the values of $1 \mu \mathrm{g} / \mathrm{ml}$ reported by Garcia-Martos et al. (2002). However, the same is not true for C. laurentii, which showed MICs of $2 \mu \mathrm{g} /$ $\mathrm{ml}$ in our tests suggesting again a primary resistance to this antifungal. Based on these results, the testing of greater numbers of clinical and environmental isolates should be considered in order to not only profile the species behavior against the antifungal, but also to be attentive to resistance developments and future research on its mechanisms.

There are no reports of resistance to amphotericin B by $C$. albidus and $C$. laurentii even considering the different methodologies employed by several authors (Bauters et al. 2001, Chen et al. 2001, Averbuch et al. 2002).

All strains tested showed $\mathrm{MIC}_{90}$ values $\geq 1 \mu \mathrm{g} / \mathrm{ml}$ for itraconazole, suggesting primary resistance in environmental strains. The values were lower for $C$. laurentii and high for C. uniguttulatus. The highest $\mathrm{MIC}_{50}$ value was found for $C$. albidus, indicating that these strains are more resistant to itraconazole when compared to $C$. neoformans var. neoformans and C. laurentii. Environmental C. neoformans var. neoformans resistance to itraconazole is seldom reported in the literature (Garcia-Martos et al. 2002). Also, Brazilian studies (Franzot \& Hamdan 1996, Alves et al. 2001, Moraes et al. 2003) did not show the presence of environmental C. neoformans strains resistant to this antifungal. However, $80 \%$ of $C$. albidus isolates were resistant to itraconazole as were $C$. uniguttulatus strains. Most strains of $C$. laurentii were sensitive to the drug confirming results by Garcia-Martos et al. (2002). Other reports indicate different resistance levels to itraconazole in clinical C. laurentii isolates (Bauters et al. 2001, Chen et al. 2001, Averbuch et al. 2002, Serena et al. 2004).

Fluconazole is one of the main drugs used in the treatment of meningeal cryptococcosis and frequently also in maintenance therapy. Most cases of $C$. neoformans meningitis resistant to the drug were reported in AIDS patients after long treatment periods and prophylaxis (Franzot \& Hamdan 1996, Alves et al. 2001). MIC ranges for fluconazole were quite wide for all strains, but were smaller for $C$. laurentii suggesting that the antifungal is more active in this strain, which confirms previous results reported by Garcia-Martos et al. (2002) and Serena et al. (2004).

Most strains were resistant in vitro to 5-fluorocytosine, the drug with the highest $\mathrm{MIC}_{50}$ for all strains tested. Furthermore, clinical use of 5-fluorocytosine in the treatment of $C$. neoformans infections has been frequently associated to in vivo resistance development, despite in vitro variable results from different studies (Franzot \& Hamdan 1996, Alexander \& Perfect 1997, Alves et al. 2001, Moraes et al. 2003). Also, clinical isolates of $C$. laurentii and $C$. albidus show variable resistance to the antifungal (Kordossis et al. 1998, Bauters et al. 2001, Averbuch et al. 2002). Quindos et al. (2004) in a study in Spain, reported resistance indexes as high as $80 \%$, with MIC values above $128 \mu \mathrm{g} / \mathrm{ml}$.

Barchiesi et al. (1994) and Espinel-Ingroff et al. (1992) in comparative studies confirmed the correlation of broth macrodilution and microdilution techniques for in vitro antifungal susceptibility testing. The APs for broth macro and microdilution techniques in this report were considered adequate, since all combinations had percentages above $81 \%$ for \pm 2 dilutions. Aller et al. (2000) consider that APs above $80 \%$, in \pm 2 dilutions is indeed an indication of a good correlation.

Previous reports by Barchiesi et al. (1994) concerning C. neoformans and antifungals fluconazole, 5fluorocytosine and amphotericin B were confirmed in this study, showing APs above $92 \%$, in \pm 2 dilutions. The lower APs found for itraconazole suggest the necessity of further and better evaluation of the applied methods. It is possible that method optimization by a strict control of interfering variables, such as antifungal solubility, inoculum concentration and time of incubation might improve these percentages. It is important to emphasize the in vitro and in vivo correlation studies, that allow analysis and understanding of clinical data and to determine MIC ranges for $C$. neoformans and other emergent clinical strains.

According to the reported results, it is concluded that environmental isolates of $C$. neoformans var. neoformans, C. albidus, C. laurentii, and C. uniguttulatus may show high MICs for certain drugs, which preliminarily suggest in vitro primary resistance. Amphotericin B and fluconazole showed the best APs for all strains tested, while for itraconazole and 5-fluorocytosine, APs were dependent on the strain.

\section{REFERENCES}

Alexander BD, Perfect JR 1997. Antifungal resistance trends towards the year 2000. Implications for therapy and new approaches. Drugs 54: 657-678.

Aller AI, Martin-Mazuelos E, Gutierrez MJ, Bernal S, Chavez M, Recio FJ 2000. Comparison of the Etest and microdilution method for antifungal susceptibility testing of Cryptococcus neoformans to four antifungal agents. $J$ Antimicrob Chemother 46: 997-1000.

Alves SH, Oliveira LT, Costa JM, Lubeck I, Casali AK, Vainstein MH 2001. In vitro susceptibility to antifungal agents of clinical and environmental Cryptococcus neoformans isolated in Southern of Brazil. Rev Inst Med Trop São Paulo 43: 267-270. 
Averbuch D, Boekhout T, Falk R, Engelhard D, Shapiro M, Block C, Polacheck I 2002. Fungemia in a cancer patient caused by fluconazole-resistant Cryptococcus laurentii. Med Mycol 40: 479-484.

Barchiesi F, Colombo AL, McGough DA, Rinaldi MG 1994. Comparative study of broth macrodilution and microdilution techniques for in vitro antifungal susceptibility testing for yeasts by using the National Committee for Clinical Laboratory Standards proposed standard. J Clin Microbiol 32: 2494-2500.

Bauters TGM, Swinne D, Boekhout T, Noens L, Nelis HJ 2001. Repeated isolation of Cryptococcus laurentii from the oropharynx of an immunocompromized patient. Mycopathologia 153: 133-135.

Chen MF, Chiou CC, Liu YC, Wang HZ, Hsieh KS 2001. Cryptococcus laurentii fungemia in a premature neonate. J Clin Microbiol 39: 1608-1611.

Espinel-Ingroff A, Kish CWJr, Kerkering TM, Fromtling RA, Bartizal K, Galgiani JN, Villareal K, Pfaller MA, Gerarden T, Rinaldi MG 1992. Collaborative comparison of broth macrodilution and microdilution antifungal susceptibility tests. J Clin Microbiol 30: 3138-3145.

EUCAST-European Committee on Antimicrobial Susceptibility Testing 2002. Discussion Document E. Dis. 7.1: Method for the determination of minimum inhibitory concentration (MIC) by broth dilution of fermentative yeasts, EUCAST, Muniz, p. 1-21.

Franzot SP, Hamdan JS 1996. In vitro susceptibilities of clinical and environmental isolates of Cryptococcus neoformans to five antifungal drugs. Antimicrob Agents Chemother 40: 822-824.

Garcia-Martos P, Noval JF, Garcia-Tapia A, Marin P, Puerto JL, Sepulveda A 2002. Sensibilidad a antifúngicos de especies de Cryptococcus de interés clínico. Med Clin 119: 211-213.

Johnson LB, Bradley SF, Kauffman CA 1998. Fungaemia due to $C$. laurentii and a review of non-neoformans cryptococcaemia. Mycoses 41: 277-280.

Kamalam A, Yesudian P, Thambiah AS 1977. Cutaneous infection by Cryptococcus laurentii. Br J Dermatol 97: 221-223.

Kordossis T, Avlami A, Velegraki A, Stefanou L, Georgakopoulos G, Papalambrou C, Legakis N 1998. First report of Cryptococcus laurentii meningitis and a fatal case of Cryptococcus albidus cryptococcaemia in AIDS patients. Med Mycol 36: 335-339.
Kunova A, Krcmery V 1999. Fungaemia due to thermophilic cryptococci: 3 cases of Cryptococcus laurentii bloodstream infections in cancer patients receiving antifungal. Scand $J$ Infect Dis 31: 328.

Loison J, Bouchara JP, Guiho E, Gentile L, Cimon B, Chennebault JM, Chabasse D 1996. First report of Cryptococcus albidus septicaemia in an HIV patient. $J$ Infect 33: 139-140.

Mccurdy MD, Morrow JD 2001. Ventriculitis due to Cryptococcus uniguttulatus. South Med J 94: 65-66.

Moraes EM, Primola NS, Hamdan JS 2003. Antifungal susceptibility of clinical and environmental isolates of Cryptococcus neoformans to four antifungal drugs determined by two techniques. Mycoses 46: 164-168.

NCCLS-National Commitee For Clinical Laboratory Standards 2002. Publication of M27-A2 2002: Reference Method for Broth Dilution Antifungal Susceptibility Testing of Yeasts: approved standard, 2nd ed., Villanova, p. 1-30.

Pfaller MA, Barry AL 1994. Evaluation of a novel colorimetric broth microdilution method for antifungal susceptibility testing of yeast isolates. J Clin Microbiol 32: 1992-1996.

Quindos G, Ruesga MT, Martin-Mazuelos E, Salesa R, AlonsoVargas R, Carrillo-Munoz AJ, Brena S, San-Millan R, Ponton J 2004. In vitro activity of 5-fluorocytosine against 1,021 Spanish clinical isolates of Candida and other medically important yeast. Rev Iberoam Micol 21: 63-69.

Rodriguez-Tudela JL, Rodero L, Córdoba S 1998. Estado actual de las pruebas de sensibilidad a los antifúngicos: nuevas aproximaciones. I Curso Hispano-Argentino de Micologia Médica, Instituto Nacional de Enfermidades Infecciosas Dr. Carlos G. Malbran, Buenos Aires.

Rodriguez-Tudela JL, Rodero L, Cuenca-Estrela M, Cordoba S 2000. Determinación de la resistencia a los antifúngicos en el laboratório. III Curso Hispano-Argentino de Micologia Médica, Instituto de Salud Carlos III, Espanha.

Serena C, Pastor FJ, Ortoneda M, Capilla J, Nolard N, Guarro J 2004. In vitro antifungal susceptibilities of uncommon basidiomycetous yeasts. Antimicrob Agents Chemother 48: 2724-2726.

Souza LKH, Fernandes OFL, Kobayashi CCBA, Passos XS, Costa CR, Lemos JA, Souza-Junior AH, Silva MRR 2005. Antifungal susceptibilities of clinical and environmental isolates of Cryptococcus neoformans in Goiânia city, Goiás, Brazil. Rev Inst Med Trop São Paulo 47: 253-256. 